\title{
Value Co-creation in the Health Service Ecosystems: The Enabling Role of Institutional Arrangements
}

\author{
Maria Vincenza Ciasullo ${ }^{1}$, Silvia Cosimato ${ }^{1}$, Rocco Palumbo ${ }^{1} \&$ Alessandra Storlazzi ${ }^{2}$ \\ ${ }^{1}$ Dept. of Management \& Innovation Systems, University of Salerno, Fisciano, Italy \\ ${ }^{2}$ Suor Orsona Benincasa, University of Naples, Italy \\ Correspondence: Maria Vincenza Ciasullo, Dept. of Management \& Innovation Systems, University of Salerno, \\ 84084, Via Giovanni Paolo II, no. 132, Fisciano, Salerno, Italy.
}

Received: October 17, 2017

doi:10.5539/ibr.v10n12p222
Accepted: November 8, 2017

Online Published: November 16, 2017

URL: https://doi.org/10.5539/ibr.v10n12p222

\begin{abstract}
The health care service system is currently undergoing a profound revolution that has put the patient at the core of health outcome co-creation. Patient-centered care could be associated with Service Dominant Logic that looks at co-creation process as a dynamic resources' integration between actors. From this standpoint, the need for a broader vision of value creation process towards a service ecosystem perspective is emerging. This paper includes an overview of the scientific literature and reports on a narrative case study analysis concerning the "International Consortium for Health Outcomes Measurement" in an attempt to nourish the debate on the different ways that multiple actors can collaboratively shape a health service ecosystem. Findings reveal that co-creation practices, involving multiple actors who belong to different ecosystem levels, led to mutual adjustments and to on-going shared changes. These processes directly influenced health outcome creation, which is reframed in light of patients' needs, expectations, and experiences. Therefore, patients are assuming the role of health outcome "co-creator", interacting with all other ecosystems actors (e.g. physicians, institutions, $\mathrm{NGO}_{\mathrm{s}}$, health managers, ICTs providers etc.). This study represents a first and preliminary attempt to investigate a real example of dynamic resources' exchange, based on the contribution of multiple interacting actors and on the role of interdepend and interacting institutions in value practices.
\end{abstract}

Keywords: health service ecosystem, co-creation practices, health outcome, case study

\section{Introduction}

\subsection{The Evolving Health Care Arena}

The Health care sector across Europe is undergoing a profound revolution, which is ultimately aimed at making it fitting with people (Erwin \& Krishnan, 2016). On the one hand, the health care service system absorbs a large share of national budgets (Palumbo, 2017a); on the other hand, health care organizations have been variously argued to be unable to effectively meet the special needs of patients (Porter and Tiesberg, 2004; Palumbo, Annarumma, \& Musella, 2017). Several scholars have claimed that this situation has been the by-product of the focus of health policies on costs and efficiency improvements (Wenzl, Naci, \& Mossialos, 2017; Wildavsky, 2018).

In the last few years, the scientific literature patronized the emergence of a value-based view in the health care service system, where the key issue is increasing value for patients (Porter, 2010). In other words, “...It's not the number of services provided or the volume of services delivered that matters, but the value" (Kaplan and Porter, 2011, p. 49). Drawing on these insights, outcomes are considered to be more important than output and performance, even though they are more difficult to be assessed (Palumbo, 2017 ). The critical role of value in health care is also influenced by the shift from a paternalistic and illness-centered approach towards a patient-centred approach (Porter, 2010; McCormack et al., 2011; Porter \& Lee, 2013; Frank et al., 2014), according to which patients are considered as active partners of the health care providers, who are able to deeply contribute in the design and delivery of care (Farmer, Taylor, Stewart, \& Kenny, 2017). In light of these considerations, both scholars and practitioners agree on the need for promoting the establishment of a co-creating patient-provider relationship in the health care service system (Michie \& Williams., 2003; Quaschning et al., 2013; Braithwaite \& Schrodt, 2014). 
In spite of both the success of the reconceptualization of patients as partners of the health care professionals (Michie \& Williams, 2003; Ostrom et al., 2010 and Mirzaei et al, 2013) and the importance attached to value co-creation in the health care service system (Ostrom, 2010), it could be assumed that a real patient involvement is yet to come (Wilson, et al., 2017). In fact, patient involvement is prevented by a prevailing bio-medical approach to care, which considers the patient a passive target of medical services and information (Berry and Bendapudi, 2007; Payne et al., 2008; Coulter, 2012). This traditional understanding of health services' provision neglects that patient-provider interactions are at the core of value co-creation processes (Epstein \& Street, 2011). In other words, the bio-medical approach to care overlooks that the patients play a crucial role in enhancing the health outcomes which could be achieved through their engagement in the provision of care (Street, et al., 2009). This interaction contributes to co-create "... a patient-centered health regimen to improve patient outcomes" (Cox and Agee, 2012, p. 1).

\subsection{The Rise of the Ecosystem Perspective in the Health Care Service System}

In the health care realm, value co-creation process is intended to foster the value of the provided services, the quality of care, and patients' psycho-physical wellbeing, merging professional expertise and patients' experience (McColl-Kennedy et al., 2012). Sticking to the Service-Dominant Logic (S-DL) principles, value co-creation should be understood as a dynamic process, in which multiple actors are concomitantly involved, sharing and integrating their resources through a mutually agreed value proposition that shapes a network of dense relationships (O'Grady et al., 2008; Frow et al., 2016). Beyond the social and physical environment, personal features (inter alia, culture, values and motivation) are argued to play a deep influence on the way resources are exchanged and integrated among the actors. Indeed, several recent contributions emphasized that value co-creation ultimately relies on the establishment of a positive and comfortable experience for patients (Helkkula et al., 2012; Sandstrom et al., 2008; Russo-Spena \& Mele, 2012). However, value co-creation does not merely concern the patient-provider dyad; rather, it involves other interacting actors, such as informal caregivers and social workers, enacting an overlapping between different value co-creation processes (Hardyman, et al., 2015).

This paves the way for a systemic approach to co-creation (Wieland, et al., 2012), which offers a more dynamic understanding of the way multiple actors share, integrate and create those resources which are able to improve the quality of care (Chughtai \& Blanchet, 2017). Embracing an ecosystem perspective, it is possible to represent health care system as a set of multiple interacting actors that share and re-combine their resources at all ecosystem levels to create mutual value (Rowe \& Hogarth, 2005). This approach has pushed health care to go beyond the traditional and linear interaction at the root of patient-provider dyad (Gummesson, 2009), in an attempt to put at the core of its sustainability the evolving adaptiveness to complex and unpredictable environments (Palumbo, Cosimato, \& Tommasetti, 2017). Health outcomes rise from the above-mentioned adaptation, that is actors' ability and disposition to share, exchange and create new resources, through the implementation of specific and collaborative practices. Obviously, this process may contribute to an on-going improvement in health services' quality and effectiveness.

\subsection{Research Aims and Contents}

This paper aims at examining "in action" the value co-creating dynamics which characterize a health care service system, pointing out how the interactions between the patients, the providers of care, and the other entities which populate the health care system contribute in the generation of a unique value. The article is organized as follows. In the second section, the theoretical framework on which the study rely is presented: for this purpose, an overview of the prevailing scientific literature dealing with S-D Logic is depicted, in order to: 1) figure out the distinguishing attributes of the service ecosystem perspective; 2) discuss its suitability to the health care service domain; and 3) stress the importance of co-creation practices in shaping a lively and sustainable health care service ecosystem. The third section depicts the research design and methods: a case study approach was taken, in order to collect first hand data about value co-creation practices in the health care service ecosystem. Findings are included in the fourth section of the manuscript, which includes the narration of co-practices arising from the case study. The fifth section critically discusses the findings, suggesting conceptual and managerial implications, as argued in the sixth and concluding section of the article.

\section{Theoretical Framework}

\subsection{The Conceptual Evolution of $S$-DL}

S-D Logic is an evolving construct (Vargo \& Lush, 2008), which has rapidly moved from its early conceptualization by Vargo and Lusch (2004) to a wide array of coexisting theoretical advancements (Joiner \& Lusch, 2016). In an attempt to provide a systematization of the pillars of S-D Logic, it is possible to summarize its ten Foundational Premises (FPs) suggested by Vargo and Lusch $(2004,2008)$ into five key axioms (Greer et al. 
2016) which are the cornerstone of a consistent conceptual framework (Vargo and Lusch, 2016). The following bullet points report the five axioms on which the S-D Logic relies:

- Axiom 1: Service is the fundamental basis of exchange;

- Axiom 2: Value is co-created by multiple actors, always including the beneficiary;

- Axiom 3: All social and economic actors are resource integrators;

- Axiom 4: Value is always uniquely and phenomenologically determined by the beneficiary;

- Axiom 5: Value co-creation is coordinated through actor-generated institutions and institutional arrangements.

In other words, S-D Logic focuses on the dynamics at the roots of value co-creation processes (Payne et al., 2008) and the concept of value-in-use, which could be also reframed as a value-in-context (Chandler and Vargo, 2011) and, consequently, as a value-in-social-context (Edvardsson et al., 2011). From this point of view, S-D Logic embraces an extensive service-based ecosystem perspective (Vargo and Lusch, 2011, 2016), which is fitting to different service environments, including: logistics, health care, information technology, sports, tourism, and others.

Lusch and Vargo $(2014$, p. 24$)$ defined a service ecosystem as “...a relatively self-contained, self-adjusting system of resource integrating entities that are connected by shared institutional logics and mutual value creation through service exchange". The service ecosystem is established on the joint contribution of several different actors, who are linked together in a dense network of relationships, which pave the way for the integration of internal and external resources. Some essential processes shape a service ecosystem (Lush and Nambisan, 2015), such as:

1) the establishment of a shared view, which intertwines a set of cognitively distant actors;

2) the design and the implementation of a participative architecture aimed at coordinating these actors;

3) and the facilitation of interaction among actors themselves.

A service ecosystem is built upon multiple, but deeply nested levels (Chandler and Vargo, 2011; Akaka et al., 2013), defined as micro, meso, and macro. The micro-level arises from dyadic interactions between firms and customers. These interactions represent the building blocks of the meso-level, where the collaboration and cooperation of organizations and communities push towards its evolution in a macro-level. Here, several institutions and associations design and disseminate shared norms, culture, language, and rules to foster the proper functioning of both the micro and the meso levels. The different ecosystem levels are merged through specific value propositions, that make the actors who populate the service ecosystem able to access and combine the resources needed for their viability. The dynamic nature of service ecosystems relies on actors' disposition to share and apply their resources, influencing their availability and offering attractiveness, as well as the ability of the ecosystem itself to adapt its configuration to a complex and ever-changing environment.

In a critical domain such as health care, the service ecosystem perspective offers an extensive interpretation of both value co-creation practices and co-creating interactions between the actors who operate at the different health care service ecosystem levels. Recognizing the inner complexity of service encounters, the scientific literature (Vargo and Lusch, 2010, 2016; Akaka et al., 2013; Greer et al., 2016) is still calling for a better understanding of the way co-creation practices contribute to the shaping of a service ecosystem through the interconnection, interaction and collaboration among and between different actors. This is especially true in the health care service system, which show several peculiarities as compared with other service environments (Palumbo, 2016).

Among others, Frow et al. (2016) recently conceptualized the health care service system in light of a service ecosystem perspective, identifying the micro-, meso- and macro-levels as depicted in Figure 1. Going more into details, different institutional actors interact at the macro-level, such as state health authorities, professional associations, labour unions, health insurers; differently, the main interacting actors at meso-level are hospitals, clinics, local health support agencies, and care home and hospice. At micro-level, the dyadic and/or triadic interactions occurring between patients, informal caregivers, and health care providers, are relevant. An additional ecosystem level - the mega-level - could be included among the layers of the health care service ecosystem (Chandler \& Vargo, 2011). At this level, co-creation practices involve - among others - government agencies, health funding bodies, regulatory bodies, and media (Frow et al., 2016). 


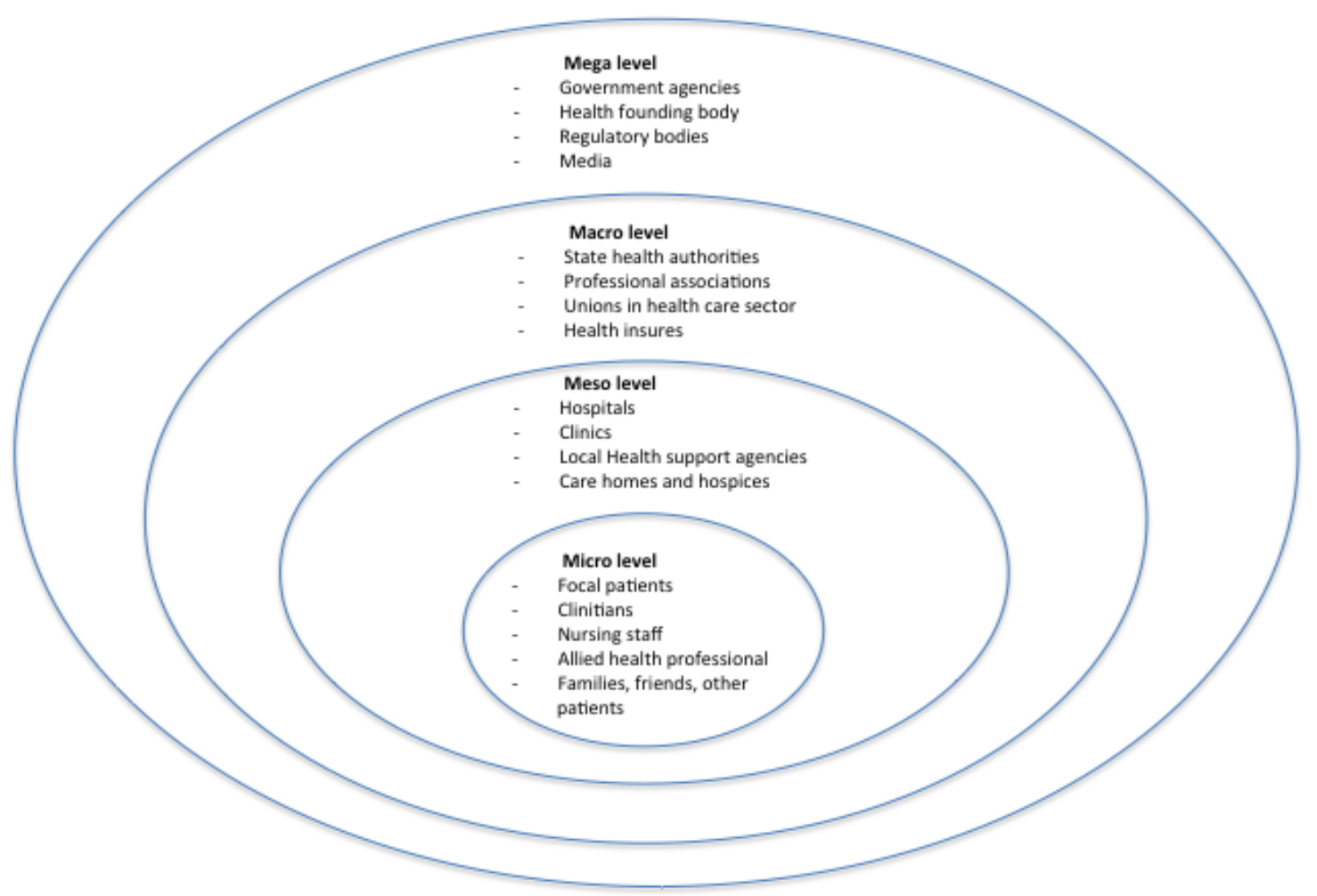

Figure 1. A representation of the Health care service ecosystem (Adapted from Frow, et al., 2016)

As an illustrative example, on-line forums and social networks - such as Facebook - could be placed at the mega level of the health care ecosystem; thus, they allow actors to widely discuss health-related issues, such as the effects of new procedures and treatments related to specific diseases (e.g. diabetes) (Robertson, et al., 2014). In fact, patients - who populate the micro-level of the service ecosystem - are likely to use digital tools as a medium, that makes them able to share their knowledge and participate to value co-creation (or value co-destruction) processes (van der Eijk, et al., 2013). The sharing of knowledge can also occur in other dedicated social networks, where patients look for new and more specific information, reporting what they find and contributing to improve both personal and common resources (Dosani et al., 2014).

It is interestingly to note that the processes of resource integration that occur at other ecosystem levels foster the creation of additional integration processes, which impact on the mega level. For the sake of the argument, patients and health care professionals' associations - operating at the macro level - may assess the reliability of health-related information provided on the internet, thus offering a "roadmap" to collect, access and use health information to actors at the mega level (Dalmer, 2017). Health care organizations - which are located at the meso level - are able to foster the establishment of meaningful patient-provider relationships, thus setting the conditions for value co-creation during the medical encounter (Annarumma \& Palumbo, 2016). Last but not least, heterogeneous factors such as history, culture, politics, law, health or pharmaceutical lobbies concern the mega level and affect the definition of national orientation towards health care (Frow et al., 2016).

Ultimately, a health care service ecosystem is based on actor-to-actor (A2A) interactions that create and recreate a supportive organizational logic to service exchange and value co-creation, that is an outcome in which service providers and users (i.e. patients and informal caregivers) contribute to value creation, sharing and integrating their resources. From this standpoint, a service ecosystem can be conceptualized as a participative architecture, which allows to better understand the inner collaborative nature of value co-creation. This participative architecture offers a road map that encourages actors to participate to service exchanges and provides the mechanisms intended to the coordination, integration and synchronization of different ecosystem actors (Nambisan \& Sawhney, 2011). This enables the ecosystem actors to cooperate without a strong hierarchical structure, that is typical of bureaucratic organizations. 


\subsection{Value Co-creation in a Health Care Service Ecosystem}

Embracing the service ecosystem perspective (Siltaloppi, et al., 2016), the health care service system can be considered as a set of actors who interact within and between different ecosystem levels following specific dynamics that lead them to share, built and rebuilt their resources. These interacting processes are at the core of value co-creation or co-destruction dynamics (Peters, 2016). In line with these arguments, one of the primary concerns of S-D Logic literature (Vargo and Lush, 2004, 2008, 2016; Vargo et al., 2008; Akaka et al., 2012) is the understanding of how different actors contribute to value co-creation and how they collaboratively share their own resources. A large part of the existing scientific literature delves into the interactions occurring at micro-level (Lush and Vargo, 2006; Chandler and Vargo, 2011; Hardyman et al., 2015): here, the interactions are built upon a dyadic (patient-provider) logic, according to which the actors are willing to share and combine their resources to achieve a joint outcome.

Recently, some scholars (McColl-Kennedy, 2012, 2015; Frow et al., 2016) have begun to explore value co-creation practices at meso, macro and even mega levels, emphasizing how actors are involved in value co-creation practices by sharing their resources. Interacting with other actors (e.g. institutions, suppliers, other health providers, Non-Government Organisations - NGOs, and families), users co-create service experiences at different ecosystem levels (Epp and Price, 2008; Schau et al., 2009; Vargo and Lush, 2011; McColl-Kennedy et al., 2012). At the core of this view there is the understanding of services as contextually interpreted and experienced by individuals (Vargo and Lush, 2008; Echeverri and Skålén, 2011; Helkkula et al., 2012).

Several authors, aware of the opportunity to go beyond the traditional dyadic relationship between providers and patients, developed a relational logic, based on actor-to-actor interactions (Lusch and Vargo, 2006, 2014; Akaka et al., 2012; Vargo and Lush, 2012). In this scenario, an ecosystem approach offers a broader and systemic understanding of the relationships occurring among these actors (Henderson and Palmatier, 2010). In fact, an ecosystem perspective puts a growing emphasis on both the contribution of each actor to the whole system and on how the interactions occur among all the interacting actors (Thomas and Autio, 2014). The use of a broader perspective, which focuses on the interaction among multiple actors (Araujo et al., 2008), help to better understand "how" actors influence each others and "what" is the intensity of such influence in an ever-changing ecosystem (Frow et al., 2016). Value co-creating practices are helpful in making this point.

Generally speaking, practices are "...routinized ways in which bodies are moved, objects are handled, subjects are treated, things are described and the world is understood" (Reckwitz, 2002, p. 250). Therefore, they are intended as actions joined together by the interaction among actors (Schatzki, 2005). Moving towards a micro, meso, macro, and mega level approach to value co-creation activities, the practice theory can support the investigation of how multiple actors' interactions affect the process of value co-creation at the intra- and interlevels of a service ecosystem. Such a conceptual lens offers an alternative approach to value creation (Schau et al., 2009). From this point of view, patients' participation in the co-creation of the service experience is based on the interaction with others actors placed at different levels of their service ecosystems (Vargo and Lusch, 2011; McColl-Kennedy et al., 2012). Drawing on these considerations, Frow et al. (2016) identified a typology of eight co-creation practices (CPs) which could be applied to health care. These eight practices are (Frow et al, 2016):

- $\mathrm{CP} \# 1$ : Practices that endow actors with social capital;

- $\quad$ CP\#2: Practices that provide an ecosystem with a shared language, symbols, signs and stories;

- $\quad \mathrm{CP} \# 3$ : Practices that shape an actor's mental model;

- $\mathrm{CP} \# 4$ : Practices that impact the ecosystem, created or constrained by the physical structures and institutions that form their contexts;

- $\quad \mathrm{CP} \# 5$ : Practices that shape existing value propositions and inspire new ones;

- CP\#6: Practices that impact access to resources within an ecosystem:

- $\quad \mathrm{CP} \#$ 7: Practices that forge new relationships, generating interactive and/or experiential opportunities;

- $\mathrm{CP} \# 8$ : Practices that are intentionally co-destructive creating imbalance within the ecosystem.

These eight co-creation practices are the core of the conceptual framework which inspires the analysis of value co-creation practices in a health service eco-system that is proposed in this study. It eventually aims at filling the identified gap in the literature, in an attempt to contribute to a better understanding of how multiple actors' interactions are able to affect the shape and the functioning of the health care service ecosystem, thus influencing its ability to self-contain and self-adjust available resources in a relational logic of value co-creation (Lusch and Vargo, 2014, p. 24). 


\section{Research Design and Strategy}

\subsection{Methods}

The case study methodology (Yin, 2014) is a fitting method to handle the topic dealt with in this research, that is the definition of multi-actor participation in those co-creation practices which concur to shape a health care service ecosystem. This approach entails "... a research strategy focused on the comprehension of those dynamics characteristic of specific contexts" (Eisenhardt, 1989, p. 532). Moreover, it facilitates the investigation of a phenomenon within its context, collecting data from various sources in an attempt to provide a tentative answer to the questions that have inspired this study (Baxter and Jack, 2008). Therefore, the case study method paves the way for a punctual analysis of health care systemic nature and the way actors interact to achieve health outcomes.

Drawing on Iwakabe (2015), this case study took the form of a "narrative", according to which no quantitative results are measured and presented. Sticking to the story metaphor (Simons, 2009) and the narrative case study method (Etherington \& Bridges, 2011), heterogeneous information arising from ICHOM's partner histories were collected, organized, and interpreted in light of the eight Co-creation Practices defined by Frow et al. (2016). Data were obtained from several secondary sources (e.g. reports, handbooks, papers, video-interviews, corporate blogs, and corporate social networks) accessed surfing ICHOM's corporate web sites. Evidence were independently searched by the authors in the period from January, 2016 to June, 2016.

At a first stage, the collected data were arranged according to a specific research protocol, which was devised $a d-h o c$ by the authors for the purpose of this research. It was based on a digital worksheet that researcher could independently access to analyse the retrieved data. No time limitations were set to collect relevant data. Therefore, all data published in the ICHOM website until June, 2016 were taken into consideration. Moreover, in an attempt to increase the depth of this study, no exclusion criteria based on the authorship of the published data were used. Hence, both data published by the ICHOM and by ICHOM's partners were contemplated for the purpose of this research. Lastly, when needed, additional evidence was searched in the web sites of the ICHOM's partners, in order to improve the reliability and the consistency of this study. Each member of the research team classified the collected data according to the eight Co-creation Practices (CP) defined by Frow et al. (2016). Afterward, all the narrations on value co-creation practices were individually analysed by the members of the research team, who aggregated individual reports, in order to confront them and elicit agreements and disagreements. When disagreements emerged, the histories were critically reviewed and discussed until consensus was reached.

Several rules were agreed to guide both the individual analysis and the debate between the members of the research team: 1) report the data in sufficient detail to justify your conclusions; 2) mention all relevant results, including those that run counter to expectation; 3) be sure to include small effect sizes (or statistically nonsignificant findings) when theory predicts large (or statistically significant) ones; 4) do not hide uncomfortable results by omission; and 5) do not include individual scores or raw data with the exception, for example, of single-case designs or illustrative examples. As a result of this step-by-step process, a joined research report was arranged, which inspired the findings of this research. In the spirit of data sharing (encouraged by APA and other professional associations and sometimes required by funding agencies), raw data, including study characteristics and individual effect sizes used in a meta-analysis, can be made available on request by interested readers.

\subsection{The Unit of Analysis}

The International Consortium for Health Outcomes Measurement (ICHOM) is a non-profit organization founded by a joint initiative of different scientific, medical, and business organizations including Harvard University, Boston Consulting Group, and Karolinska Institutet. ICHOM focused its mission on a general re-thinking of the international health care system, supporting the development and the spread of shared systems dedicated to the measurement and reporting of the contribution of socio-economic actors to health outcomes.

ICHOM's mission is “...to unlock the potential of value-based health care by defining global Standard Sets of outcome measures that really matter to patients for the most relevant medical conditions and by driving adoption and reporting of these measures worldwide" (www.ichom.org, 2017, last accessed on May, 3th 2017). To date, ICHOM has been able to map 13 diseases and define their related set of standards. According to the collected information and the theoretical framework proposed by Frow et al. (2016), ICHOM can be placed at the mega level of a health service ecosystem. In fact, it is an international NGO interacting and bringing together, according to a co-creation logic, different actors (e.g. local and national institutions, health providers, physicians, patients, etc.) in order to achieve high quality health outcomes. 


\section{Findings}

Each story described and analysed below shows its own peculiarities in terms of informant actors, nationality, organizations, and roles. The features that mainly stood out in the narrated co-practices were actors' involvement, collaboration, and cooperation in achieving high quality health care outcomes. Moreover, sticking to a systemic interpretation of investigated practices, ICHOM facilitated the interaction between and among multiple actors belonging to different and interacting systems and making them able to learn from each other and improve their performances. The brief histories reported below show the way the different actors belonging to the ICHOM ecosystem contributed to specific health care co-creation practices, highlighting the insights which arise from the enacted practices and pointing out the ecosystem level they impacted on.

\subsection{Practices that Endow Actors with Social Capital: CP\#1}

The HCF Research Foundation is a charitable trust, which supports research and enquiry into the provision, administration and delivery of health services in Australia. Wayne Adams, the Director of the HFC Research Foundation, stated:

"We have established a partnership with ICHOM because we recognize the critical need to shift the Australian health care system towards one based on outcomes, not simply outputs, and see our work with ICHOM as supporting that transformation."

Moreover, he declared:

"The collaboration with ICHOM reflects a growing recognition that driving value in health care requires cross-stakeholder engagement. HCF (...) collaborates with ICHOM to respond to health care expenditure cutting off. (...) The partnership with ICHOM made HCF able to offer an economic support to people who couldn't pay for their care path, respecting ICHOM sta ndards".

HCF active engagement in ICHOM represents a co-creation practice which is intended to feed social capital for all the actors who interact within the health care service ecosystem, this influencing their social position and role in the functioning of the latter. The reframe of the roles that different agents play in the health care ecosystem may entail the arrangement of ad hoc initiatives, which allow to enhance the effectiveness and appropriateness of health services provision, without implying additional health costs.

As far as the experience of users is concerned, a patient who was engaged in one of ICHOM's online forums shared her experience in order to provide other patients with relevant information to face challenging health issues:

"I was expecting (...) and, having lost my first baby, I was determined to avoid a reprise of the tragedy (...). I had been thinking about how I could help improve health care structurally and systemically. The head echo cardiographer said that my second baby had TOF (Tetralogy of Fallot) and he would likely need multiple open-heart surgeries, my focus became medical condition and its outcomes. (...) I tried to take the best decisions about hospitals, surgeons, and treatments. I visited seven children's hospital, meeting with cardiac surgeons and asking them directly about the best treatment. Then I gathered some of the information I was looking for. My long quest for good outcomes led to a hospital in Boston, and it was there that my son was born. He had many surgeries and spent three months in the NICU (neonatal intensive care unit). He had additional surgeries and more than two dozen oesophageal dilations. (...) Despite everything, he now is happy and has no altitude or exercise restrictions. I think that medical errors must be documented alongside successes, and this information should be made accessible to both clinicians and patients".

Patients' active engagement in ICHOM's online forum represents a practice which is aimed at creating and sharing new knowledge. In the specific case reported above, the share of individual patient experience was intended to assist other women with babies suffering from TOF, providing them with both psychological support and information to properly navigate the health care system. From this point of view, ICHOM itself seems to perform as an ecosystem, which involves a wide array of agents, each of which contribute in maintaining it vivid and viable.

\subsection{Practices that Provide an Ecosystem with a Shared Language, Symbols, Signs and Stories: CP\#2}

ICON is a global provider of outsourced drug development services to biopharma, medical device, government, biosimilar, and generic organisations; also, it is one of the most relevant ICHOM's partners. As regards with this partnership, its Chief Operating Officer (COO) argued: 
"We are building around the world with institution registries measuring ICHOM Standard Sets. (...) Partners have been added to the network all over the world. (...) 54 health care facilities in India, Dubai, Mauritius, and Sri Lanka, have started measuring the Coronary Artery Disease Standard Set".

Similarly, an ICHOM's manager for the development of outcome measurement Standard Set reported:

"We (...) are supporting implementation projects across the US, UK, France, Australia, and, with over a hundred more institutions expressing interest in measuring our outcome sets. At the end of 2015, we launched our Implementation Communities, an ICHOM support model that invites groups of value-oriented institutions to move through the implementation process collaboratively. (...) As part of our on-going mission to promote outcomes measurement and share best practices publicly, we have migrated much of the content from our subscriber-only Implementation Network to a new file library located on ICHOM.org. This content is now freely available to all registered ICHOM.org users".

The de velopment of a global Standard Sets is a co-creation practice which is aimed at providing all ICHOM's partners with a general and universally agreed protocol which supports them in outcome definition and measurement, making them perfectly comprehensible, and sharable within the whole service ecosystem. In other word, this co-creation practice involves the gradual establishment of the health care service ecosystem's infrastructure, paving the way for the definition of shared language, symbols, signs and stories among the actors who contribute to its functioning.

\subsection{Practices that Shape an Actor's Mental Model: CP\#3}

Also, the $\mathrm{COO}$ of ICON stated:

"We are proud to bring our clinical and technical expertise in health outcomes and real-world data to help ICHOM to launch the first global health outcomes benchmarking program".

The global health outcomes benchmarking program is intended to support health providers in changing their practices and following the most successful ones, in an attempt to facilitate a wider adoption by the side of all service ecosystem actors (e.g. Governments, Institutions, Professional Associations, Medical Staffs, Patients, Families, etc.). Emphasizing this point, the Vice President Strategy and New Program Development at ICHOM claimed:

"The ICHOM has also launched the ICHOM TechHub, (...) a review-based directory of electronic tools for outcomes measurement. (...) Using the TechHub, health care providers and administrators can view profiles and reviews, sort and filter options based on key criteria, and request additional information and virtual demonstrations from those that ultimately meet their organization's preferences and needs. (...) Working alongside care providers around the world, we have learned that there is no 'one-size-fits-all' technology solution to support outcomes measurement. The diversity of geography and functionality of these platforms will allow the TechHub to serve as a valuable resource for hospitals around the world interested in measuring ICHOM Standard Sets".

ICHOM's TechHub is crucial to encourage the actors who populate the health service ecosystem in changing the way they approach outcome measurement, facilitating their access to specific and certified tools, which enable them to participate in co-creation practices and to effectively share their resources.

The Memorial Sloan Kettering Cancer Centre, the world's oldest and largest private cancer center, participates in the ICHOM ecosystem. Focusing on the role of this organization in such an ecosystem, one of its Informing Doctor reported:

"Sloan Kettering engages more proactively with physicians in the selection of risk factors for adjustment of their approach to prostate cancer care, also through the design of their own report cards. Thanks to a secure web portal, urologists can access a report of their average risk-adjusted outcomes, aggregated over all of their patients who have undergone radical prostatectomy. In this way, urologists can compare their rate with colleagues'rates, defining their own case mix".

The web portal, being based on a logic of performance improvement and risk reduction, allows to compare data. From this point of view, it is able to deeply influence co-creation practices, as well as behaviours and activities of different physicians, shaping the actors'mental model and setting the conditions for value co-creation. 


\title{
4.4 Practices that Impact the Ecosystem: $\mathrm{CP \# 4}$
}

FORCE-TJR is a Massachusetts-based research registry, which develops tools with which to record the patients' assessment of the success and failure of their surgery, and conducting research to guide both clinical care and health care policy. Its Managing Director argued:

"Rather than building new infrastructures, some U.S. providers have outsourced the collection of outcome data. Consequently, some providers were equipped with centralized registry, where the staff collected comparable data at complementary time points from multiple sites, reporting the information back to each of these various sites. Data collection process was based on patients' direct involvement, who, evaluating their treatment, contributed to co-create indicative measures about physical structures, care paths, provided services, and staff performances. (...) After signing the consent form, patients could complete the questionnaire either through a web-based survey or on paper that can be scanned. The adjusted data were stored in the national registry, and are accessible by the treating surgeon any time through a secure website".

The development and the implementation of a centralized registry helps health providers to extend and adopt new and emerging rules, norms, and procedures which are able to support the existing and, possibly, new practices. Therefore, these types of co-creation practices deeply impact the ecosystem, affecting the informal structures and institutions that form the contexts in which the different actors interact.

4.5 Practices that Shape Existing Value Propositions and Inspire New One: CP\#5.

The COO of Providence Health and Services, a not-for-profit Catholic health care system operating multiple hospitals across 5 State in US and an ICHOM Strategic Partner, claimed:

\begin{abstract}
"Implementing a value-based strategy is on the mind of nearly every health care organization in the U.S. The shifting from cost-based strategies to value-based strategies (...) led some ICHOM's providers to shape Working Groups of leading physicians, patient representatives, and outcomes experts from registries. (...) Our Working Group members are volunteers who have equal voice in determining a shared outcome. (...) We find that nearly every element of their value strategies builds on and is strengthened by one thing: the ability to measure outcomes."
\end{abstract}

The implantation of value-based strategies, which are directed to improve outcomes, shrink costs, and enhance the appropriateness of care, may lead to the definition of new value propositions, which are relevant for all the actors involved in the functioning of the health care service ecosystem. Echoing these considerations, an informant senior manager at Massachusetts General Hospital, the largest teaching hospital of Harvard Medical School, admitted:

"The Division of Population Health Management team knew it needed a better process for determining who was best served by resource-intensive procedures. Rather than require that physicians follow rigid protocols, the Division created a decision support system to help clinicians determine when a procedure was indicated, based on a patient's clinical circumstances. Procedures were integrated into the electronic medical record, and patients received videos and handouts explaining the risk and benefits of the various treatment options, as well as personalized consent forms that adapted those risk and benefits for their specific circumstances. The entire system was informed and refined by on-going tracking of outcomes".

In this specific circumstance, the reframe of actors' value proposition was aimed at properly facing the gradual shift from volume-based fee-for-service contracts to risk-based population ones, striving for reducing the effects of such a change on the individual viability. Co-creation practices allowed to frame a new interaction approach between the patients and the providers of care, which - in turn - enhanced outcomes through on-going evaluation.

\subsection{Practices that Impact Access to Resources within an Ecosystem: CP\#6}

ICHOM Vice President of Research and Development revealed:

"At the end of 2013, we created a new website that better reflects who we are and what we do. The web site is continually enhanced, especially thanks to the constant partners' contribution (...) who contribute to enrich its contents, publishing User Generated Contents (...) about practices, general information, and reporting inefficiencies, emergencies, and the related answer. This led to the creation of a community based common meaning sharing among a flurry of new partnerships."

The launch of ICHOM new web site and the related social tools contributed to offer a virtual space in which the 
actors populating the health care service ecosystem can access and share resources. Obviously, the greater opportunities of resource integration involve greater ability of value co-creation and, therefore, increased well-being for those who participate in the functioning of the health care service system.

Similarly, an Informant Doctor of Wexner Medical Center, a multidisciplinary academic medical center of the Ohio State University, reporting that his clinic created some questionnaires to capture patients' experiences and feelings as a quality standard, pointed out:

"During the check in, each patient was asked to complete the questionnaire, in order to make the staff able to scan it into the patient's Electronic Medical Record (EMR) in order to track outcomes.

(...) Medical staff could refer to the reports and manually trend data, in order to control the evolution of care paths."

The adequate functioning of a service ecosystem basically relies on the access to timely and relevant information, which are an essential ingredient of the recipe for fostering collaborative and co-creating relationships between the different ecosystem actors.

\subsection{Practices that Forge New Relationships, Generating Interactive and/or Experiential Opportunities: CP\#7}

In the opinion of the ICHOM Vice President:

"The frequent ICHOM's conferences are organized to support physicians and practitioners in meeting and sharing their experiences in terms of achieved outcomes. (...) Sharing their experiences, showing problems that they have faced, and, in several cases, publishing specific papers and/or articles, they can feed new practices able to improve their offering".

From this point of view, ICHOM performs as a crucial platform establishing new forms of relationships between the actors and generating greater opportunities to co-create value. In particular, ICHOM facilitates health outcomes assessment, embracing a patient-centered approach. Moreover, it attempts to deeply engage all relevant actors in outcome measurement, strengthening and intensifying relationships within ecosystem.

In line with these points, an informant physician of Memorial Sloan Kettering Cancer Centre reported:

"A patient felt very safe recording outcomes, even about sensitive issues, on a computer."

Consequently, in 2009 his centre started to use the Web Survey Core, an online platform that allows patients to report their outcomes directly to their physicians. Patients could also complete the survey during their waiting time in the clinic through a tablet. After this, the doctor could have a comprehensive view of the ans wers that respects patients' anonymity. In this way, doctors might be able to focus their attention on problem solving, rather than on the other issues, including data collection. This was very supporting in medical issues related to critical disease such as prostate cancer, about which patients were less confident to talk about, preferring to report about it in an anonymous way. Of course, these data are especially relevant for the purposes of shared health decision-making.

\subsection{Practices that are Intentionally Co-Destructive Creating Imbalance within the Ecosystem: CP\#8}

An informant doctor of Memorial Sloan Kettering Cancer Centre reported on the way physicians reacted to the implementation of a new program of electronic survey. The doctor told that in his centre medical staff didn't use a digital program, considering it too complex and time expensive. Consequently, they felt:

"We were wasting their time, especially in overbooked days".

Health care professionals were also critic of this tool, considering the report it provided hard to interpret and offering little useful information. The negative reaction of Memorial Sloan Kettering Cancer Centre physicians led to the emergence of disrupting practices, based on actors' defection from the ecosystem. Likely, such a co-destruction dynamic was generated by an inadequate involvement of health care professionals in the design and implementation of the co-creation practice.

\section{Discussion}

The different co-creation practices analysed in this paper are expression of a patient-centered approach to care. However, their impact is not limited to a micro ecosystem level, which focuses on the dyadic patient-provider relationship; rather their effect spread to all the different ecosystem levels. The various actors who populate the health care service ecosystem (including patients, health providers, health care organizations, professional associations, community of patients, and so on) are engaged, in several different ways, in a co-creation effort, contributing to health outcome improvement. Ultimately, health care co-practices affect the long-term outcomes which could be achieved in the health care service system, relying on resource integration and redefinition of 
individual value propositions. According to a recursive and circular logic, systemic and agreed value propositions enable the whole health service ecosystem to improve its effectiveness and efficiency.

Following this red-thread running through all the co-practices, the following lessons can be learned:

1) In terms of practices that endow actors with social capital (CP1), the first narration emphasizes the importance of trust and cooperation among the interacting actors at the mega ecosystem le vel. In the reported narration, trust arises from the ICHOM's ability to enhance the density of interactions. The active engagement of ICHOM's partners feeds and distributes social capital among all the interacting actors, influencing their position, influence, and attractiveness on the service ecosystem (Schau et al., 2009). From this point of view, it is not surprising that, benefitting from the collaboration with ICHOM, HCF was able to establish a better relationship with patients, especially those belonging to the marginalized group of the population.

2) The second narration, which concerns the meso ecosystem level, underlines that knowledge - as well as the personal experience of patients with the illness - is shared both among people suffering from similar diseases (bridging ties) and with health care providers (linking relationships), who can benefit from such a resource to arrange a health treatment which is tailored to the special health needs of each patient.

3) In terms of practices that provide an ecosystem with a shared language, symbols, sign and stories, the adoption of a common language fosters the reliability of shared information, making all the interacting actors able and willing to co-create value (Akaka et al., 2014). The transparency at the root of Standard Sets discussed above prevents an ambiguous analysis of health care practices, minimizing the risks of value co-destruction. This result can be achieved defining and sharing experiences or, alternatively, preventing negative practices that may lead to the misuse of available resources. Indeed, a consistent and transparent measurement of health outcomes based on shared Standards Sets (language) can improve patient experience and outcomes quality, concomitantly reducing health care costs.

4) The case study narration has pointed out some interesting practices, which are able to shape the actors' mental model. In particular, ICHOM's outcome benchmarking program positively affected the dynamic interactions among different actors at the same and at different levels, leading to radical change of the mental model and driving multiple actors' activities towards continuous improvement. In this case, ICHOM's leading activities and its central position within the health care service ecosystem had a deep influence on other interacting actors, feeding and/or enabling the ecosystem's dynamic configuration. In a global health care system, this change may lead to the improvement of health performance and, consequently, of the offered services. In addition, this led to an overall improvement in the quality of life.

5) The practices that ICHOM enacted in order to influence the ecosystem, created or constrained by the physical structures and the institutions that form their contexts, highlight the ability to improve care pathways through resources' integration. In the reported narration, physical resource (National Registry sponsored by ICHOM) dematerialization, outsourced to a specialized external provider, imply a deep redesign of the clinic's physical structure, building a new intangible infrastructure. Consequently, the implementation of the National Registry puts knowledge sharing at the core of the process of health services' provision, making patients free to report their care path experience and their demands for health services' improvement. It is evident that this structural change can potentially affect and change the way actors interact, paving the way for new emerging co-practices. This change benefits not only the treatment of a single patient, making it ever more personalized, but also the knowledge improvement of a single organization and of all those health care organizations that can access the register and participate in new resources (knowledge) creation.

6) In terms of practices that shape existing value propositions and inspire new ones, the emergence of a value-based approach has led some of ICHOM's providers to shape new plots of relations among actors and to develop new ways to share their resources, in order to create new value propositions, that allow an increase of achievable health outcomes. In particular, new value propositions led to the abandoning of cost-based strategies and to the implementation of value-based strategies, aimed at enhancing outcomes and lowering costs. In other words, the health service ecosystem has been shaped by the actions of multiple actors, who have integrated resources in innovative ways, thus contributing to new offering creation.

7) Some value co-creation practices affect the access to resources within a health care service ecosystem. The development and the implementation of an open platform highlight the logic on which ICHOM's and all the interacting actors shape the service ecosystem. This platform enables an on-going resource sharing and, at the same time, contributes to the creation of new resources, facilitating the contribution of actors who, sticking to their specific role, can publish and share User Generated Contents (UGCs). Therefore, the open-access platform enables actors' participation to specific co-creation practices, and makes them able to access new resources 
generated merging their own resources.

8) ICHOM's online forum makes multiple actors able not only to share experiences and resources, but also to create new ones (such as knowledge), in order to enhance performances and improve the offered services. This practice also allows individual actors to seek and share knowledge about their health-related condition though the online forum. It is evident that the enhancement of performances and services involves an increase of the wellbeing for the whole health service ecosystem.

Last but not least, the narration pointed out some practices that are intentionally co-destructive creating imbalance within the health care service ecosystem. A co-disruptive practice has been found among the medical staff of a U.S. provider. It highlighted a voluntary resistance to changing managerial routines, due to the implementation of a new physical resource (an electronic survey). In this case, the resistance disrupted the ability to create positive health outcomes. It has also to be reported that the negative attitude of medical staff towards the new physical resource was mainly due to the different logic that guides practice in different ecosystems - in our case, the health service ecosystem in which the electronic survey has been implemented and the ICT service ecosystem in which it has been developed - and has sometimes led to unbalanced interactions among actors who participated in various embedded ecosystems (Akaka et al., 2013).

\section{Conclusions and Implications}

This paper supports the role of value co-creation practices in a health service ecosystem and contributes to the debate on health service research. In particular, our study firstly contributes to the empirical application in a specific context of Frow et al.'s (2016) theoretical framework, nourishing the scientific debate. ICHOM was presented as an extreme case (Eisenhardt, 1989) in shaping a service ecosystem, enabling not only resources' sharing and coordination (knowledge), but also new resources creation (shared visions and norms), which involves the on-going ecosystem adjustment. The adoption of a patient-centred approach, according to which health outcome are reconceptualised, represents the starting point of value creation, which led to organizational, physical, behavioural, and emotional changes.

In addition, this research highlights the underlying processes at the roots of both value co-creation and resources' integration in a network of a multiple interacting actors (Ostrom, et.al. 2015; Ciasullo, et al., 2017). Co-creation practices created by different actors, belonging to different ecosystem levels, show a mutual adjustment and contribute to ongoing and shared changes. From this point of view, health outcome co-creation takes place not only in light of patient's demands, needs, expectations, and experiences, but also "with" the patient, who becomes a key partner of health care professionals and a fundamental value co-creator. For this purpose, the ability of various mediating actors (e.g. ICTs providers, non-profit organizations, social workers) is crucial, since they support in correctly interpreting and using the resources that patients offer in order to redefine the health care services' offering. Following this logic, a process of mutual adjustment between these different actors arises at all the ecosystem levels (micro, meso, macro, and mega). Such an adjustment is endorsed by a gradual change in individual value propositions, through the activation of synergistic interactions which, in turn, promote a creative adaptation (Mele et al 2014).

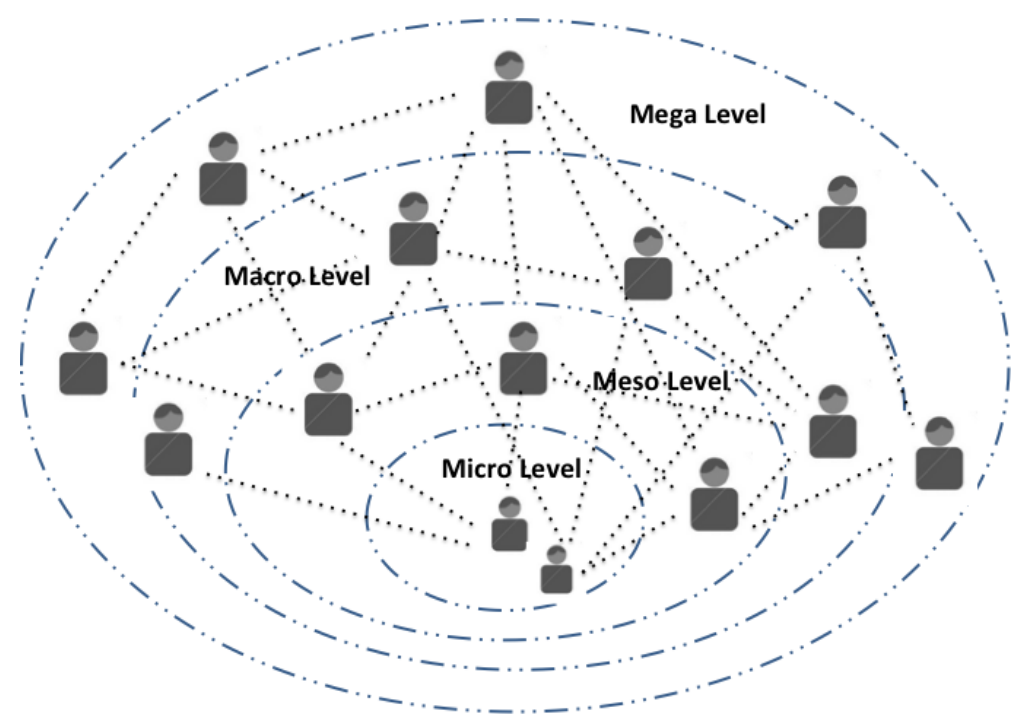

Figure 2. Resources' exchange among and between actors of different ecosystem levels 
Also, this research has interesting managerial implications. First of all, health care providers should be encouraged to establish better relations with the various actors, at the micro, meso, macro, and mega le vels, to co-create value. Also, appropriate strategies should be designed and implemented to avoid the emergence of value co-destruction dynamics, which entail negative health outcomes. Moreover, the lessons learned analysing the co-creation practices assist managers in redesigning the shape of the health care service system according to a systemic view (Barile, et al., 2016).

The research is somewhat limited by a focus just on ICHOM co-practices; for this reason, findings could not be generalized to similar health care service ecosystems. With this in mind, further investigations should focus on other experiences of co-creation practices, embracing either a descriptive or a comparative approach. Also, more attention should be paid to the peculiar business models that would allow health care organizations to properly function in a health care service ecosystem. Lastly, further developments are needed to better understand: (1) the way co-creation practices produce stronger and more reliable relationships between the health care service ecosystem's actors, and (2) the role of ICTs in shaping service ecosystems.

\section{References}

Adams, C. A. (2002). Internal organisational factors influencing corporate social and ethical reporting: Beyond current theorizing. Accounting, Auditing \& Accountability Journal, 15(2), 223-250. https://doi.org/10.1108/09513570210418905

Akaka, M. A., Corsaro, D., Kelleher, C., Maglio, P. P., Seo, Y., Lusch, R. F., \& Vargo, S. L. (2014). The role of symbols in value cocreation. Marketing Theory, 14(3), 311-326. https://doi.org/10.1177/1470593114534344

Akaka, M. A., Vargo, S. L., \& Lusch, R. F. (2012). An exploration of networks in value cocreation: A service-ecosystems view. Review of Marketing Research, 9 (Special Issue), 13-50. https://doi.org/10.1108/S1548-6435(2012)0000009006

Akaka, M. A., Vargo, S. L., \& Lusch, R. F. (2013). The complexity of context: a service ecosystems approach for international marketing. Journal of Marketing Research, 21(4), 1-20. https://doi.org/10.1509/jim.13.0032

Annarumma, C., \& Palumbo, R. (2016). Contextualizing Health Literacy to Health Care Organizations. Exploratory Insights. Journal of Health Management, 18(4), 611-624. https://doi.org/10.1177/0972063416666348

Araujo, L., Kjellberg, H., \& Spencer, R. (2008). Market practices and forms: Introduction to the special issue. Marketing theory, 8(1), 5-14. https://doi.org/10.1177/1470593107086481

Barile, S., Lusch, R., Reynoso, J., Saviano, M., \& Spohrer, J. (2016). Systems, networks, and ecosystems in service research. Journal of Service Management, 27(4), 652-674. https://doi.org/10.1108/JOSM-09-2015-0268

Baxter, P., \& Jack, S. (2008). Qualitative case study methodology: Study design and implementation for novice researchers. The qualitative report, 13(4), 544-559.

Berry, L. L., \& Bendapudi, N. (2007). Health care a fertile field for service research. Journal of Service Research, 10(2), 111-122. https://doi.org/10.1177/1094670507306682

Braithwaite, D. O., \& Schrodt, P. (Eds.). (2014). Engaging theories in interpersonal communication: Multiple perspectives. Sage Publications.

Chandler, J. D., \& Vargo, S. L. (2011). Contextualization and value-in-context: How context frames exchange. Marketing Theory, 11(1), 35-49. https://doi.org/10.1177/1470593110393713

Chughtai, S., \& Blanchet, K. (2017). Systems thinking in public health: a bibliographic contribution to a meta-narrative review. Health Policy and Planning. Published on-line ahead of print on January, 6th 2017. https://doi.org/10.1093/heapol/czw159

Coulter, A. (2012). Patient engagement-what works?. The Journal of ambulatory care management, 35(2), 80-89. https://doi.org/10.1097/JAC.0b013e318249e0fd

Cox, C. L. \& Agee, E. J. (2012). Application of a marketing concept to patient-centered care: co-producing health with heart failure patients. Online journal of issues in nursing, 17(2), A1.

Dalmer, N. K. (2017). Questioning reliability assessments of health information on social media. Journal of the Medical Library Association, 105(1), 61-68.

Dosani, S., Harding, C., \& Wilson, S. (2014). Online Groups and Patient Forums, Current Psychiatry Reports, 
16(11), 507. https://doi.org/10.1007/s11920-014-0507-3

Echeverri, P., \& Skålén, P. (2011). Co-creation and co-destruction: A practice-theory based study of interactive value formation. Marketing theory, 11(3), 351-373. https://doi.org/10.1177/1470593111408181

Edvardsson, B., Tronvoll, B., \& Gruber, T. (2011). Expanding understanding of service exchange and value co-creation: a social construction approach. Journal of the Academy of Marketing Science, 39(2), 327-339. https://doi.org/10.1007/s11747-010-0200-y

Eisenhardt, K. M. (1989). Agency theory: An assessment and review. Academy of management review, 14(1), 57-74.

Epp, A. M., \& Price, L. L. (2008). Family identity: a framework of identity interplay in consumption practices. Journal of Consumer Research, 35(1), 50-70. https://doi.org/10.1086/529535

Epstein, R. M., \& Street Jr, R. L. (2011). The Values and Value of Patient-Centered Care. Annals of Family Medicine, 9(2), 100-103. https://doi.org/10.1370/afm.1239

Erwin, K., \& Krishnan, J. A. (2016). Redesigning health care to fit with people Design expertise can improve delivery of care, $B M J, 354(4536)$.

Etherington, K., \& Bridges, N. (2011). Narrative case study research: On endings and six session reviews. Counselling and Psychotherapy Research, 11(1), 11-22. https://doi.org/10.1080/14733145.2011.546072

Farmer, J., Taylor, J., Stewart, E., \& Kenny, A. (2017). Citizen participation in health services co-production: a roadmap for navigating participation types and outcomes. Australian Journal of Primary Health, Published on-line ahead of print on June, $23^{\text {rd }} 2017$. https://doi.org/10.1071/PY16133

Frank, L., Basch, E., \& Selby, J. V. (2014). The PCORI perspective on patient-centered outcomes research. Jama, 312(15), 1513-1514. https://doi.org/10.1001/jama.2014.11100

Frow, P., McColl-Kennedy, J. R., \& Payne, A. (2016). Co-creation practices: Their role in shaping a health care ecosystem. Industrial Marketing Management, 56, 24-39. https://doi.org/10.1016/j.indmarman.2016.03.007

Greer, C. R., Lusch, R. F., \& Vargo, S. L. (2016). A service perspective. Organizational Dynamics, 1(45), 28-38. https://doi.org/10.1016/j.orgdyn.2015.12.004

Gummesson, E. (2009). Marketing as Networks: The Birth of Many-to-Many Marketing. Stockholm: Publishing House Djursholm.

Hardyman, W., Daunt, K. L., \& Kitchener, M. (2015). Value co-creation through patient engagement in health care: a micro-level approach and research agenda. Public Management Review, 17(1), 90-107. https://doi.org/10.1080/14719037.2014.881539

Helkkula, A., Kelleher, C., \& Pihlström, M. (2012). Characterizing value as an experience: implications for service researchers and managers. Journal of Service Research, 15(1), 59-75. https://doi.org/10.1177/1094670511426897

Henderson, C. M., \& Palmatier, R. W. (2010). Understanding the relational ecosystem in a connected world. In: S.H.K. Wuyts, M.G. Dekimpe, E. Gijsbrechts, \& F.G.M.(Rik) Pieters (Eds.) The connected customer: The changing nature of consumer and business markets (pp. 37-76), New York: Routledge.

Iwakabe, S. (2015). Introduction to case study special issue-- case studies in Japan: Two methods, two worldviews. Pragmatic Case Studies in Psychotherapy, 11(2), 65-80. https://doi.org/10.14713/pcsp.v11i2.1902

Joiner, K. A., \& Lush, R. F. (2016). Evolving to a new service-dominant logic for health care. Innovation and Entrepreneurship in Health, 3(1), 25-33. https://doi.org/10.2147/IEH.S93473

Kaplan, R. S., \& Porter, M. E. (2011). How to solve the cost crisis in health care. Harvard Business Review, 89(9), 46-52.

Lusch, R. F., \& Nambisan, S. (2015). Service Innovation: A Service-Dominant Logic Perspective. MIS Quarterly, 39(1), 155-176. https://doi.org/10.25300/MISQ/2015/39.1.07

Lusch, R. F., \& Vargo, S. L. (2006). Service-dominant logic: reactions, reflections and refinements. Marketing theory, 6(3), 281-288. https://doi.org/10.1177/1470593106066781

Lusch, R. F., \& Vargo, S. L. (2014). Service-dominant logic: Premises, perspectives, possibilities. Cambridge University Press. 
McColl-Kennedy, J. R., Cheung, L., \& Ferrier, E. (2015). Co-creating service experience practices. Journal of Service Management, 26(2), 249-275. https://doi.org/10.1108/JOSM-08-2014-0204

McColl-Kennedy, J. R., Vargo, S. L., Dagger, T. S., Sweeney, J. C., \& van Kasteren, Y. (2012). Health care customer value cocreation practice styles. Journal of Service Research, 15(4), 370-389. https://doi.org/10.1177/1094670512442806

McCormack, L. A., Treiman, K., Rupert, D., Williams-Piehota, P., Nadler, E., Arora, N. K., \& Street, R. L. (2011). Measuring patient-centered communication in cancer care: a literature review and the development of a systematic approach. Social science \& medicine, 72(7), 1085-1095. https://doi.org/10.1016/j.socscimed.2011.01.020

Mele, C., Gummesson, E., \& Polese, F. (2016). The Naples Forum on Service Developing theory through the practices of a community. Marketing Theory, 16(2), 266-268. https://doi.org/10.1177/1470593115608077d

Michie, S., \& Williams, S. (2003). Reducing work related psychological ill health and sickness absence: a systematic literature review. Occupational and environmental medicine, 60(1), 3-9. https://doi.org/10.1136/oem.60.1.3

Mirzaei, M., Aspin, C., Essue, B., Jeon, Y. H., Dugdale, P., Usherwood, T., \& Leeder, S. (2013). A patient-centred approach to health service delivery: improving health outcomes for people with chronic illness. BMC health services research, 13(1), 1. https://doi.org/10.1186/1472-6963-13-251

Nambisan, S., \& Sawhney, M. (2011). Orchestration processes in network-centric innovation: Evidence from the field. The Academy of Management Perspectives, 25(3), 40-57. https://doi.org/10.5465/AMP.2011.63886529

O’Grady, N. P., Barie, P. S., Bartlett, J. G., Bleck, T., Carroll, K., Kalil, A. C., et al. (2008). Guidelines for evaluation of new fever in critically ill adult patients: 2008 update from the American College of Critical Care Medicine and the Infectious Diseases Society of America. Critical care medicine, 36(4), 1330-1349. https://doi.org/10.1097/CCM.0b013e318169eda9

Ostrom, A. L., Bitner, M. J., Brown, S. W., Burkhard, K. A., Goul, M., Smith-Daniels, V., et al. (2010). Moving forward and making a difference: research priorities for the science of service. Journal of Service Research, 13(1), 4-36. https://doi.org/10.1177/1094670509357611

Ostrom, A. L., Parasuraman, A., Bowen, D. E., Patricio, L., Voss, C. A., \& Lemon, K. (2015). Service research priorities in a rapidly changing context. Journal of Service Research, 18(2), 127-159. https://doi.org/10.1177/1094670515576315

Ostrom, E. (2010). Beyond markets and states: polycentric governance of complex economic systems. Transnational Corporations Review, 2(2), 1-12. https://doi.org/10.1257/aer.100.3.641

Palumbo, R. (2016). Contextualizing co-production of health care: a systematic literature review. International Journal of Public Sector Management, 29(1), 72-90. https://doi.org/10.1108/IJPSM-07-2015-0125

Palumbo, R. (2017 $)$. Toward a new conceptualization of health care services to ins pire public health. Public national health service as a "common pool of resources". International Review on Public and Nonprofit Marketing, 14(3), https://doi.org/ 10.1007/s12208-017-0175-1.

Palumbo, R. (2017b). Exploring the Divide between Output and Outcome Measures in Health Care. Journal of Health Management, Published on-line ahead of print on October, $5^{\text {th }} 2017$. https://doi.org/10.1177/0972063417727622

Palumbo, R., Annarumma, C., \& Musella, M. (2017). Exploring the meaningfulness of healthcare organizations: a multiple case study. International Journal of Public Sector Management, 30(5), 503-518. https://doi.org/10.1108/IJPSM-10-2016-0174

Palumbo, R., Cosimato, S., \& Tommasetti, A. (2017). Dream or reality? A recipe for sustainable and innovative health care ecosystems. The TQM Journal, 29(6), 1-17. https://doi.org/10.1108/TQM-02-2017-0023

Payne, A. F., Storbacka, K., \& Frow, P. (2008). Managing the co-creation of value. Journal of the academy of marketing science, 36(1), 83-96. https://doi.org/10.1007/s11747-007-0070-0

Peters, L. D. (2016). Heteropathic versus homopathic resource integration and value co-creation in service ecosystems. Journal of Business Research, 69(8), 2999-3007. https://doi.org/10.1016/j.jbusres.2016.02.033

Porter, M. E. (2010). What is value in health care?. New England Journal of Medicine, 363(26), 2477-2481. 
https://doi.org/10.1056/NEJMp1011024

Porter, M. E., \& Lee, T. H. (2013). The Strategy That Wilt Fix Health Care. Harvard business review, 91(10), 50-70.

Porter, M., \& Tiesberg, E. (2006). Re-defining health care delivery. Business Harvard Press, Boston.

Quaschning, K., Körner, M., \& Wirtz, M. (2013). Analyzing the effects of shared decision-making, empathy and team interaction on patient satisfaction and treatment acceptance in medical rehabilitation using a structural equation modeling approach. Patient education and counseling, 91(2), 167-175. https://doi.org/10.1016/j.pec.2012.12.007

Reckwitz, A. (2002). Toward a theory of social practices a development in culturalist theorizing. European journal of social theory, 5(2), 243-263. https://doi.org/10.1177/13684310222225432

Robertson, N., Polonsky, M., \& McQuilken, L. (2014). Are my symptoms serious Dr Google? A resource-based typology of value co-destruction in online self-diagnosis. Australasian Marketing Journal, 22(3), 246-256. https://doi.org/10.1016/j.ausmj.2014.08.009

Rowe, A., \& Hogarth, A. (2005). Use of complex adaptive systems metaphor to achieve professional and organizational change. Journal of Advanced Nursing, 51(4), 396-405. https://doi.org/10.1111/j.1365-2648.2005.03510.x

Russo-Spena, T., \& Mele, C. (2012). "Five Co-s" in innovating: a practice-based view. Journal of Service Management, 23(4), 527-553. https://doi.org/10.1108/09564231211260404

Schatzki, T. R. (2005). Peripheral vision the sites of organizations. Organization studies, 26(3), 465-484. https://doi.org/10.1177/0170840605050876

Schau, H. J., Muñiz Jr, A. M., \& Arnould, E. J. (2009). How brand community practices create value. Journal of marketing, 73(5), 30-51. https://doi.org/10.1509/jmkg.73.5.30

Siltaloppi, J., Koskela-Huotari, K., \& Vargo, S. L. (2016). Institutional Complexity as a Driver for Innovation in Service Ecosystems. Service Science, 8(3), 333-343. https://doi.org/10.1287/serv.2016.0151

Simons, H. (2009). Case Study Research in Practice, Sage Publications, London. https://doi.org/10.4135/9781446268322

Street Jr., R. L., Makoul, G., Arora, N. K., \& Epstein, R. M. (2009) How does communication heal? Pathways linking clinician-patient communication to health outcomes. Patient Education and Counseling, 74(3), 295-301. https://doi.org/10.1016/j.pec.2008.11.015

Thomas, L. D., Autio, E., \& Gann, D. M. (2014). Architectural leverage: putting platforms in context. The Academy of Management Perspectives, 28(2), 198-219. https://doi.org/10.5465/amp.2011.0105

van der Eijk, M., Faber, M. J., Aarts, J. W., Kremer, J. A., Munneke, M., \& Bloem, B. R. (2013). Using online health communities to deliver patient-centered care to people with chronic conditions. Journal of Medical Internet Research, 15(6), e115. https://doi.org/10.2196/jmir.2476

Vargo, S. L., \& Lusch, R. F. (2004). Evolving to a new dominant logic for marketing. Journal of marketing, 68(1), 1-17. https://doi.org/10.1509/jmkg.68.1.1.24036

Vargo, S. L., \& Lusch, R. F. (2008). Service-dominant logic: continuing the evolution. Journal of the Academy of marketing Science, 36(1), 1-10. https://doi.org/10.1007/s11747-007-0069-6

Vargo, S. L., \& Lusch, R. F. (2010). From repeat patronage to value co-creation in service ecosystems: a transcending conceptualization of relationship. Journal of Business Market Management, 4(4), 169-179. https://doi.org/10.1007/s12087-010-0046-0

Vargo, S. L., \& Lusch, R. F. (2011). It's all B2B... and beyond: Toward a systems perspective of the market. Industrial Marketing Management, 40(2), 181-187. https://doi.org/10.1016/j.indmarman.2010.06.026

Vargo, S. L., \& Lusch, R. F. (2012). The nature and understanding of value: a service-dominant logic perspective. Review of Marketing Research, 9, 1-12. https://doi.org/10.1108/S1548-6435(2012)0000009005

Vargo, S. L., \& Lusch, R. F. (2016). Institutions and axioms: an extension and update of service-dominant logic. Journal of the Academy of Marketing Science, 44(1), 5-23. https://doi.org/10.1007/s11747-015-0456-3

Vargo, S. L., Maglio, P. P., \& Akaka, M. A. (2008). On value and value co-creation: A service systems and service logic perspective. European management journal, 26(3), 145-152. 
https://doi.org/10.1016/j.emj.2008.04.003

Wenzl, M., Naci, H., \& Mossialos, E. (2017). Health policy in times of austerity-A conceptual framework for evaluating effects of policy on efficiency and equity illustrated with examples from Europe since 2008. Health Policy, 121(9), 947-954. https://doi.org/10.1016/j.healthpol.2017.07.005

Wieland, H., Polese, F., Vargo, S. L., \& Lush, R. (2012). Toward a service (eco) systems. Perspectives on value co-creation. International Journal of Service Science, Management, Engineering, and Technology, 3(3), 12-24.https://doi.org/10.4018/jssmet.2012070102

Wildavsky, A. (2018). Doing Better and Feeling Worse: The Political Pathology of Health Policy. In B. Peters (Ed.), The Art and Craft of Policy Analysis (pp. 305-332). Cham: Palgrave Macmillan. https://doi.org/10.1007/978-3-319-58619-9_12

Wilson, P. M., Kendall, S., \& Brooks, F. (2007). The Expert Patients Programme: a paradox of patient empowerment and medical dominance. Health and Social Care in the Community, 15(5), 426-438. https://doi.org/10.1111/j.1365-2524.2007.00701.x

Yin, R. (2014). Case study research: Design and methods. Thousand Oaks, CA.: Sage Publishing.

\section{Copyrights}

Copyright for this article is retained by the author(s), with first publication rights granted to the journal.

This is an open-access article distributed under the terms and conditions of the Creative Commons Attribution license (http://creativecommons.org/licenses/by/4.0/). 